\title{
Comorbidities must Be Considered in Mean Platelet Volume Measurements in Patients with Adnexial Torsion
}

\author{
Ercan Varol \\ Department of Cardiology, Süleyman Demirel University School of Medicine, Isparta, Turkey
}

I read with interest the article by Koleli (1). They investigated the role of the mean platelet volume (MPV) value in the early diagnosis of patients with adnexal torsion. They found that MPV is similar between the adnexal torsion group and controls. This is an interesting and well written study. However, I want to mention some drawbacks of the study.

Firstly, the MPV measurement method is correct. On the other hand, it must not be forgotten that there is a significant relationship between MPV and blood pressure, smoking, obesity, coronary artery disease, diabetes mellitus, metabolic syndrome, inflammatory diseases and thyroid functional abnormalities (2-4). They did not report the blood glucose or blood pressure levels and body mass index of patients and controls. In addition, there is no information regarding smoking status and proportion of patients and controls with metabolic syndrome in the study. It has been reported that hypertension, diabetes mellitus, obesity, metabolic syndrome and smoking increase MPV values (2-4). Therefore, these factors should have been taken into account.

Mean platelet volume can be measured with routine complete blood counts and a simple method of evaluating platelet function. It has been reported that the thrombotic potential of larger platelets is higher than smaller ones (2). Compared with smaller ones, larger platelets have more granules, higher thromboxane A2 levels, express more glycoprotein Ib and IIb/ IIIa receptors and aggregate more rapidly with collagen $(2,5)$. MPV can be affected by many inflammatory and cardiovascular risk factors. Because of that, all confounding factors must be to taken into account. If Koleli (1) had taken these confounding factors into account, she would have possible found different results.
Ethics Committee Approval: Ethics committee approval was received for this study from the ethics committee of Süleyman Demirel University School of Medicine.

Informed Consent: N/A.

Peer-review: Externally peer-reviewed.

Conflict of Interest: No conflict of interest was declared by the authors.

Financial Disclosure: The authors declared that this study has received no financial support.

\section{REFERENCES}

1. Koleli I. Mean Platelet Volume in Early Diagnosis of Adnexal Torsion. Balkan Med J 2015;32:410-3. [Crossref]

2. Vizioli L, Muscari S, Muscari A. The relationship of mean platelet volume with the risk and prognosis of cardiovascular diseases. Int J Clin Pract 2009;63:1509-15. [Crossref]

3. Varol E, Icli A, Kocyigit S, Erdogan D, Ozaydin M, Dogan A. Effect of smoking cessation on mean platelet volume. Clin Appl Thromb Hemost 2013;19:315-9. [Crossref]

4. Varol E, Akcay S, Icli A, Yucel H, Ozkan E, Erdogan D, et al. Ozaydin M. Mean platelet volume in patients with prehypertension and hypertension. Clin Hemorheol Microcirc 2010;45:67-72.

5. Park Y, Schoene N, Harris W. Mean platelet volume as an indicator of platelet activation: methodological issues. Platelets 2002;13:301-6. [Crossref] 